Steven M. Wise

Sacudiendo la jaula: Hacia los Derechos de los animales

Tirant Lo Blanch (Valencia 2018) 394 p.

ISBN 978-84-9190-404-5

\title{
Carlo Salzani
}

Viena

Recepción: Julio 2018

Aceptación: Septiembre 2018

Cita recomendada. WISE S.M., Sacudiendo la jaula: Hacia los Derechos de los animales (Valencia 2018), rec. SALZANI C., dA. Derecho Animal (Forum of Animal Law Studies) 9/4 (2018) - https://doi.org/10.5565/rev/da.360

\section{Resumen}

En Sacudiendo la jaula Steven Wise aboga por el reconocimiento de los derechos fundamentales y el estatuto de personalidad jurídica para chimpancés y bonobos. No solamente, escribe Wise, la división entre seres humanos y animales no humanos se ha demostrado que es arbitraria, indefendible e injusta, sino que nuevos descubrimientos científicos demuestran que muchos animales no humanos, y en particular nuestros "primos" los primates, poseen capacidades cognitivas, emocionales y sociales tan similares a las nuestras como para darles derecho a la protección de la ley. Este libro quiere ser una guía practica para intervenciones concretas en favor de los derechos básicos de los homínidos no humanos.

Palabras clave: derechos de los animales, personalidad jurídica, chimpancés y bonobos, igualdad y libertad, consciencia, cognición.

\section{Abstract}

In Rattling the Cage Steven Wise argues for the recognition of the fundamental rights and the status of juridical personality for chimpanzees and bonobos. Not only, he writes, the human-animal divide has been shown to be arbitrary, untenable and unjust, but new scientific findings demonstrate that many nonhuman animals, and most notably our primate "cousins", possess cognitive, emotional and social capacities so similar to ours as to entitle them to the protection of the law. This book purports to be a practical guide for concrete interventions in favor of the basic rights of nonhuman hominids.

Keywords: animal rights, juridical personality, chimpanzees and bonobos, equality and freedom, consciousness, cognition 
Hace 10 años, el 28 de junio de 2008, la Comisión de Medio Ambiente del Congreso Español apoyó una Proposición No de Ley en la que se pedía la adhesión del gobierno al Proyecto Gran Simio y la elaboración de una ley de protección de los homínidos no humanos $^{1}$. Aunque al final dicha propuesta haya caducado, puesto que en los dos años siguientes no fue incluida en el orden del día de ninguna Comisión de Medio Ambiente, el hecho mismo de que el Congreso debatiera la cuestión dentro de un marco jurídico representó un gran paso adelante y una novedad de tamaño histórico. El Proyecto Gran Simio, iniciado el 1993, ha tenido varios altibajos y el reconocimiento de derechos fundamentales a los homínidos no humanos (orangutanes, gorilas, chimpancés y bonobos) todavía constituye un desafío importante para la mayoría de las legislaciones nacionales, pero los esfuerzos de los pasados 25 años han introducido establemente esta cuestión en la sensibilidad de nuestras sociedades y han empezado a socavar la rigidez y las resistencias de la ley. Uno de los esfuerzos teóricos más importantes y coherentes en esta dirección ha sido el libro de Steven Wise Rattling the Cage, publicado en inglés en el 2000 y cuya traducción al castellano, con el titulo Sacudiendo la jaula, ha sido publicada en la Editorial Tirant Lo Blanch en el volumen 5 de la Colección Animales y Derecho.

La contribución de este libro es importante porque Wise, más que los muchos filósofos, primatólogos o científicos comprometidos en el Proyecto Gran Simio, conoce la ley, su funcionamiento, y sobre todo sus límites y fallos: como abogado dedicado a la protección de los animales no humanos en los tribunales, y como profesor de Jurisprudencia de los Derechos Animales en varias universidades americanas, Wise sabe a dónde hay que apuntar para esperar obtener una transformación real y viable. Este libro tiene por eso una intención exquisitamente práctica, quiere servir de guía útil y eficaz para intervenciones concretas en la lucha para el reconocimiento de los derechos fundamentales de los homínidos no humanos. Es obvio que cualquier intervención práctica necesita de un aparato teórico, y por eso Wise emplea la mayor parte de su libro para construir y reforzar una argumentación racional, coherente y persuasiva, basada en datos e informaciones científicas e irrefutables, pues todo este aparato está dirigido al objetivo práctico y concreto de convencer a jueces y legisladores a reconocer por fin el estatuto de persona jurídica a los grandes simios (Wise se limita a chimpancés y bonobos, que son los "primos" más cercanos al ser humano, pero solo es el punto de partida).

Porque este es justamente el punto fundamental del libro - y de cualquier argumentación en favor de los derechos animales: solo el reconocimiento de la personalidad jurídica permitirá otorgar derechos, porque "sin personalidad jurídica uno es invisible ante la ley. No tiene derechos civiles. Podría estar muerto" (p. 25). Ser invisible ante la ley, los legisladores y los jueces significa ser una mera cosa: la partición fundamental del Ente, para la ley - que tiene sus raíces en le Derecho Romano -, se hace entre "personas" y "cosas", y los derechos sólo se atribuyen a las personas. Personas jurídicas no son tradicionalmente sólo las personas físicas, sino también estados, asociaciones, fundaciones, sociedades - pero nunca animales no humanos. Esta exclusión, argumenta Wise, es parcial, irracional e injusta y ha sido progresivamente abandonada y refutada por la ciencia y la (o por lo menos algunas) filosofía(s); pero la ley sigue anclada en esa "Gran Muralla" anacrónica que ha dividido durante miles de años los seres humanos-personas de los animales-cosas. Ha llegado el momento de derribarla y de abrir la ley a la inclusión de otros seres no humanos.

Para llegar a argumentar en favor de esta inclusión Wise toma una vía larga pero tal vez necesaria: empieza con hacer un esbozo de la historia de la exclusión y sumisión de los animales no humanos que va de los babilonios hasta la modernidad, donde se muestra la arbitrariedad y fragilidad de la división humano/animal; luego analiza el aparato del Derecho, en particular en relación a los conceptos de igualdad y libertad, para mostrar que estos

\footnotetext{
${ }^{1}$ Diario de Sesiones del Congreso de los Diputados, 25.6.2008, №48 p.26 2008 06_25 Diario de $\underline{\text { Sesiones Medio Ambiente.pdf }}$
} 
principios exigen el derrumbamiento de la división; después de señalar la flexibilidad del Common Law, o derecho anglosajón, capaz por Wise de evolucionar junto a los cambios culturales y morales de la sociedad, analiza al final chimpancés y bonobos, sobre todo en que concierne a sus capacidades mentales, tan similares a las de los seres humanos, para afirmar que, si estas capacidades constituyen el fundamento de la inclusión de los seres humanos en la comunidad moral, entonces también chimpancés y bonobos tienen que ser incluidos. En este ambicioso recorrido Wise demuestra gran sabiduría y erudición, que se extiende a muchos campos del saber, de la historia al derecho, de la primatología a la psicología animal y las neurociencias, y a la que añade ironía y agudeza; ya sólo por las muchas anécdotas que cuenta y por lo datos e informaciones científicas que ofrece al lector, el libro es muy interesante y entretenido.

No es difícil para Wise mostrar cómo, en la historia, no solamente la personalidad jurídica ha sido otorgada a entes no humanos, sino también que no todos los seres humanos han siempre sido considerados personas jurídicas y titulares de derechos. El ejemplo obvio son los esclavos, que siempre han estado más del lado de las cosas y de las propiedades que de las personas, y en efecto este ejemplo aparece en varias partes del libro. Nosotros podríamos añadir las mujeres, los niños, los "barbaros" y muchos más ejemplos, pero Wise insiste en la esclavitud, que no solo es un ejemplo más evidente, sino también que, por obvias razones históricas, es hoy mucho más presente en la conciencia social y cultural americana que en la europea. Sin embargo, los esclavos (y los otros ejemplos humanos), con respecto a los animales no humanos, tienen la ventaja de poder hablar, así que su consciencia no puede ser negada. El esfuerzo de toda la segunda mitad del libro es por tanto el de demonstrar que chimpancés y bonobos también tienen consciencia, y ello porque "la titularidad de derechos reside en la existencia de estados conscientes" (p. 186): "los derechos y la consciencia", insiste Wise, “están conectados de la misma forma en que los están la cristiandad y Jesús. La consciencia es para los derechos lo que Jesús es para la cristiandad” (p. 202).

Desde un punto de vista filosófico esta insistencia casi exclusiva en la consciencia, la cognición y las facultades mentales es problemática: significa que para tener derechos fundamentales hay que ser "como nosotros", eso es, tener las mismas características que el ser humano. Toda la teoría de los derechos animales no escapa entonces al tradicional antropocentrismo de nuestras culturas - justamente de las culturas que han oprimido y siguen oprimiendo a los animales no humanos - y, dicen los teóricos del post-humanismo, sigue siendo enteramente y esencialmente humanista. El problema no es solamente que no todos los seres humanos tienen, siempre o en algunos casos, las características definitorias y excluyentes del "ser humano" (este es el argumento de los "casos marginales"), sino más bien que, como diría el filósofo Jacques Derrida, la tradicional subjetividad humana (la del humanismo y también de la jurisprudencia) está construida y basada precisamente en el sacrificio de la (y de su) animalidad. ${ }^{2}$ Roberto Esposito añade que el concepto de "persona" es precisamente el dispositivo fundamental que opera, desde hace tres mil años y existe aún hoy con más fuerza-, esta división y este sacrificio. ${ }^{3}$ Por lo tanto, intentar superar la división humano-animal a través del Derecho y del concepto de personalidad jurídica es, para estos filósofos, un proyecto contradictorio y condenado al fracaso. Y Wise confirma su posición enteramente humanista cuando escribe: "hay alrededor de un millón de especies de animales. Muchas de ellas, como los escarabajos y las hormigas, no deberían tener estos derechos. Así que la pared [que divide personas titulares de derechos y cosas sin derechos]

\footnotetext{
${ }^{2}$ Cf. por ejemplo DERRIDA, J., «Hay que comer» o el cálculo del sujeto, entrevista con Jean-Luc Nancy, versión castellana de Virginia Gallo y Noelia Billi, revisada por Mónica Cragnolini., en Confines 17 (diciembre 2005). Edición digital de Derrida en castellano: http://www.jacquesderrida.com.ar/textos/comer bien

3 Cf. ESPOSITO, R., Tercera persona: Política de la vida y filosofía de lo impersonal (Madrid 2009); ESPOSITO, R., El dispositivo de la persona (Madrid 2011); ESPOSITO, R., Las personas y las cosas (Buenos Aires 2016).
} 
debería ser reconstruida" (p. 26). O sea: cada nueva inclusión en el "club" de los derechos sigue operando según el dispositivo de la exclusión (de otros seres).

Probablemente estos filósofos tengan razón y, a largo plazo, habrá que inventar y experimentar nuevas estrategias no (o menos) antropocéntricas. Pero Steven Wise no es un filosofo, y lo que le interesa es conseguir, hoy y no en un futuro lejano e indefinido, unos resultados concretos. Como el mismo escribe en el prólogo a la edición en castellano, su libro "no se escribió solo como un trabajo de historia, ciencia o filosofía, sino como modelo para una campaña de lucha estratégica y permanente en aras de establecer, principalmente, que los chimpancés tienen la capacidad de poseer derechos" (p. 14). Hoy, en las condiciones actuales y con el Derecho que tenemos, "la cognición es un asunto muy importante porque los derechos legales fundamentales de los animales, la barrera más sólida que hemos diseñado contra la opresión y el abuso, dependen de ella" (p. 349). Y sin personalidad jurídica no hay derechos. Un ejemplo, entre los muchos que Wise cuenta, sirve de testimonio: es la historia de Lucy, una hembra de chimpancé criada por una familia de humanos que le enseñaron el lenguaje de signos americano y a quien le gustaba tomar el té con los huéspedes de la familia. A la edad de doce años Lucy fue trasladada a un centro de rehabilitación de chimpancés en Senegal y luego a una reserva en Gambia, donde unos cazadores furtivos la mataron, le quitaron la piel y le cortaron los pies y las manos para venderlos como trofeos (p. 351). Y todo esto a pesar de sus proezas intelectuales y lingüísticas: simplemente porque no tenía personalidad jurídica.

Reconocer la personalidad jurídica a chimpancés y bonobos para otorgarles derechos fundamentales, como aboga Wise en su libro, solo sería un comienzo, pero sería un comienzo concreto, tangible, e importante. Mucho más trabajo sería después necesario para derribar, finalmente y pieza por pieza, la Gran Muralla de injusticia y violencia que separa los seres humanos de los animales no humanos. Y, en contra de lo que muchos filósofos piensan, la jurisprudencia también puede y debe desempeñar un papel fundamental en este proceso: como escribía uno de los filósofos más importantes del siglo veinte, Gilles Deleuze, la jurisprudencia, en su potencial creativo originario, constituye un escape positivo de las restricciones de la ley. ${ }^{4}$

\footnotetext{
${ }^{4}$ Cf. por ejemplo varias entrevistas en DELEUZE, G., Conversaciones (Valencia 1995), y la letra "G" en DELEUZE, G., L’Abécédaire de Gilles Deleuze, avec Claire Parnet (DVD, Paris 2004). 